\title{
Form-finding analysis of cable-membrane tensile structure with outer ring truss
}

\author{
TAO Xudong ${ }^{1}$, YU Yousheng ${ }^{1,}$ *, LI Xin ${ }^{2}$ \\ ${ }^{1}$ School of Civil Engineering, Qingdao University of Technology, Qingdao, Shandong, 266033, China \\ ${ }^{2}$ School of Civil Engineering, Shandong University of Architecture, Jinan, Shandong, 250101, China
}

\begin{abstract}
For a flexible tension structure, the first thing to do is to perform a form-finding analysis to obtain a reasonable initial state of the structure. The initial state includes the structure's own weight and the cable force distribution under the additional dead load and the corresponding geometric configuration. The geometric configuration and expectations must be ensured to be consistent with the geometry of the building. This paper used the MIDAS software to first establish the zero-state model of the structure, and then added reasonable prestress to ensure that the initial configuration of the structure under prestress, structure dead weight and additional dead load is basically the same as that under zero state, thus ensuring the feasibility and accuracy of later structural load analysis and construction process analysis, and providing ideas and methods for related projects.
\end{abstract}

\section{Introduction}

In recent years, the cable-membrane tension structure has developed rapidly. It is currently mainly used in various scenes such as stadiums, convention and exhibition centers, and airport stations. This type of structure has been more and more widely concerned and applied at home and abroad for its characteristics of light weight, high stress efficiency and easily spanning space, as well as its diverse and varied spatial forms, and it also allows people to display their imagination and creativity as they please. From the perspective of people's life and spiritual needs, the cable-membrane tension structure will have broader application prospects with the development of the times [1-3].

There are three forms of cable-membrane tensile structure, which are zero state, initial state, and load state. The zero state is also called the lofting state, which refers to the unstressed state before the cable is stretched, at which time the internal forces of the rods are all zero. The cable is tensioned from the zero state. After the tension is completed, the designed geometric configuration is reached under the combined action of the dead weight and the prestress. In this case, the initial state, and the prestress state can be obtained. The geometric configuration and internal force distribution state that the structure has when it bears other external loads except its own weight and prestress based on the initial state is called the load state. Among them, the initial state is the most important for the cable membrane tensioning structure, which serves as a link between the preceding and the following. It is mainly manifested in three aspects: First, the initial state is the state that the architectural design needs to achieve, and the geometric

\footnotetext{
* Corresponding author e-mail: yuyousheng@126.com
}

configuration under the initial state must be consistent with the expected architectural geometry; second, the rigidity of the structure itself as a flexible system is very low, and the rigidity and bearing capacity of the structure are mainly provided by the prestress distribution and geometric configuration in the initial state; third, the initial state is the target form of construction tension, that is, the prestress and geometric configuration after the tension is completed should satisfy the requirements given by the design [4].

To study the mechanical performance of the cable-membrane tensile structure, the form-finding analysis must be performed first to obtain a reasonable initial state of the structure. This paper uses the MIDAS software to first establish the zero-state model of the structure, and then add reasonable prestress to ensure that the initial configuration of the structure under prestress, structure dead weight and additional dead load is basically the same as that under zero state, thus ensuring the feasibility and accuracy of later structural load analysis and construction process analysis, and providing ideas and methods for related projects.

\section{Structural layout}

Taking a proposed stadium in Shandong Province as the engineering background, the stadium structure model is established. The structure model is composed of an upper roof structure and a lower support part. The roof structure is divided into cables, PTFE membranes, and outer ring trusses. There are 48 huge steel concrete columns arranged under the structure. The cable consists of two parts: radial cable and hoop cable. The radial cable is 
divided into 48 load-bearing cables and 48 stable cables. The hoop cable is divided into an inner ring cable and 6 structural cables. 48 steel concrete giant columns are hinged with the outer ends of 48 stabilizing cables, and the specific distribution of model components is shown in Fig. 1 to Fig. 3.

The plane projection shape of the inner and outer rings of the structural model is elliptical, with an east-west span of $218 \mathrm{~m}$, a north-south span of $249 \mathrm{~m}$, and a cantilever length of $43.61 \mathrm{~m}$. The ring truss has a height of $12 \mathrm{~m}$ and adopts the form of a three-dimensional truss with a triangular cross section. The dimensions of the model components are shown in Fig. 4 to Fig. 5. The outer end of the load-bearing cable is fixed to the upper chord of the ring truss, and the inner end is connected to the inner ring cable; the outer end of the stabilizing cable is fixed to the lower chord of the ring truss, and the inner end is connected to the inner ring cable; The two ends of the structural cable are respectively connected to the load-bearing cable and the stabilizing cable, the connecting area of the separating cable forms a cable net, which is convenient for laying the membrane material on the upper part and provides support for the membrane material.

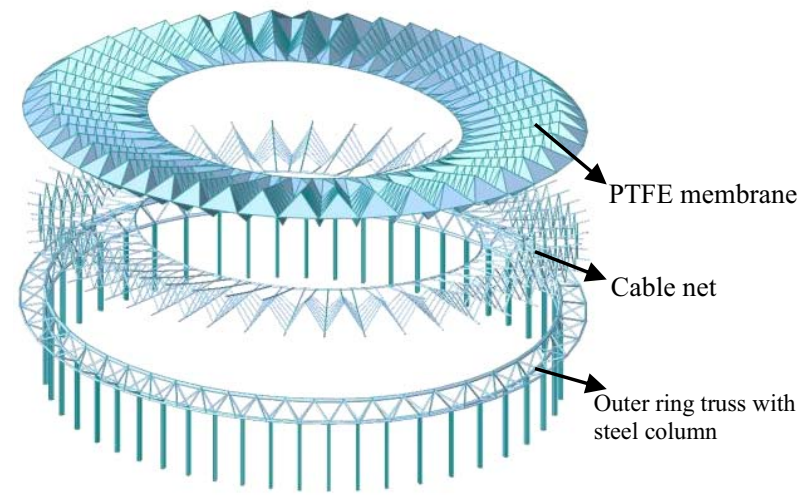

Figure 1 Exploded diagram of structural system

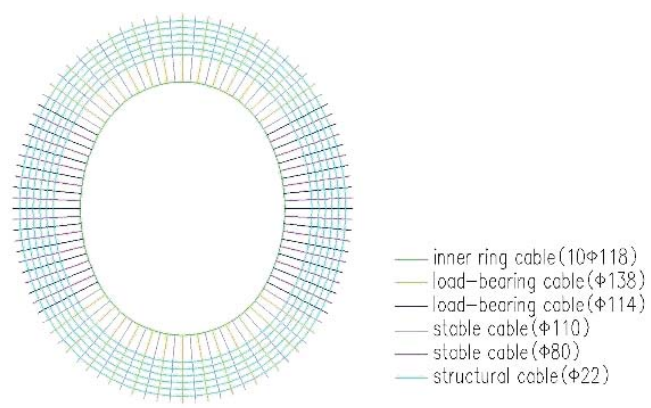

Figure 2 Plane layout of cable net components

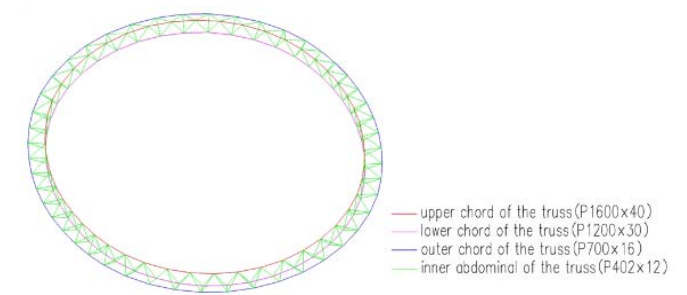

Figure 3 Plane layout of external truss components

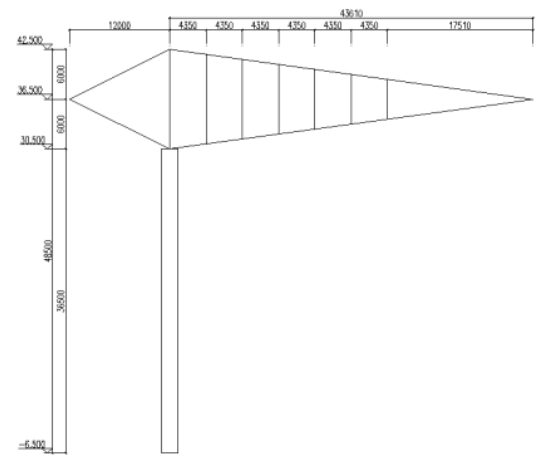

Figure 4 Elevation dimensions of model parts

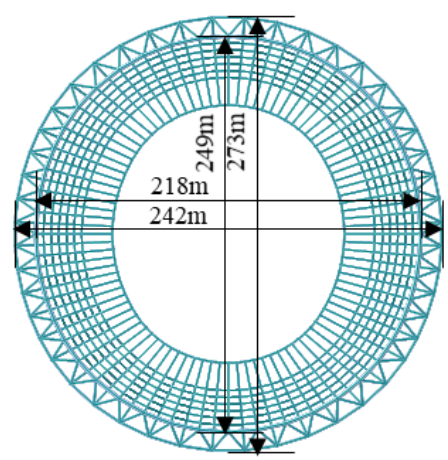

Figure 5 Plane dimensions of model parts

\section{Model parameters setting}

\subsection{Unit type}

In this structural model, the stay cable adopts only tension element, the middle cable element, the outer truss adopts the beam element, the steel concrete giant column adopts the beam element, and the PTFE membrane material adopts the three-point thin plate element.

\subsection{Material properties}

In the model, the cable net is isotropic, the elastic modulus is $1.618 \times 105 \mathrm{~N} / \mathrm{mm}^{2}$, the Poisson's ratio is 0.3 , and the bulk density is $85.49 \mathrm{KN} / \mathrm{m}^{3}$. Considering isotropy, the outer truss adopts Q235, the elastic modulus is $2.06 \times 104 \mathrm{~N} / \mathrm{mm}^{2}$, the Poisson's ratio is 0.3 , and the bulk density is $76.98 \mathrm{KN} / \mathrm{m}^{3}$. Considering the anisotropy of the film, the $\mathrm{X}$-direction elastic modulus is $1.2 \times 103 \mathrm{~N} / \mathrm{mm}^{2}$, the Poisson's ratio is 0.6 , the Y-direction elastic modulus is $8.75 \times 102 \mathrm{~N} / \mathrm{mm}^{2}$, the Poisson's ratio is 0.6 , and the Z-direction elastic modulus is taken $5.84 \times 10-5 \mathrm{~N} / \mathrm{mm}^{2}$, Poisson's ratio is 0.0123 , and the bulk density of the membrane is $16 \mathrm{KN} / \mathrm{m}^{3}$. The steel reinforced concrete giant column is a composite member composed of steel and concrete. The steel material is Q235, the elastic modulus is $2.06 \times 105 \mathrm{~N} / \mathrm{mm}^{2}$, the Poisson's ratio is 0.3 , and the bulk density is $76.98 \mathrm{KN} / \mathrm{m}^{3}$; the concrete is C40 and the elastic modulus is $3.2599 \times$ $104 \mathrm{~N} / \mathrm{mm}^{2}$, Poisson's ratio is 0.2 , and bulk density is $25 \mathrm{KN} / \mathrm{m}^{3}$. 


\subsection{Section properties}

The cross-sections of the cables in the model are all solid-web circular cross-sections, of which the load-bearing cables, stabilizing cables and structural cables are all single cables. The inner ring cables are arranged side by side in two layers, with a total of 10 cables. The cable section specifications are as follows: Two specifications of $\phi 138$ and $\phi 114$ are adopted, and two specifications of $\phi 110$ and $\phi 80$ are adopted for the stabilizer cable. The inner ring cable is $10 \phi 118$ and the structure cable is $\phi 22$. The cross-sections of the outer truss members are all tubular sections. The upper chord is $\mathrm{P} 1600 \times 40$, the lower chord is $\mathrm{P} 1200 \times 30$, the outer chord is $P 700 \times 16$, and the inner web is $P 402 \times 12$. The steel reinforced concrete giant column is a rectangular concrete-cross H-shaped steel combined section type, and the section size of the member is shown in Fig. 6 .

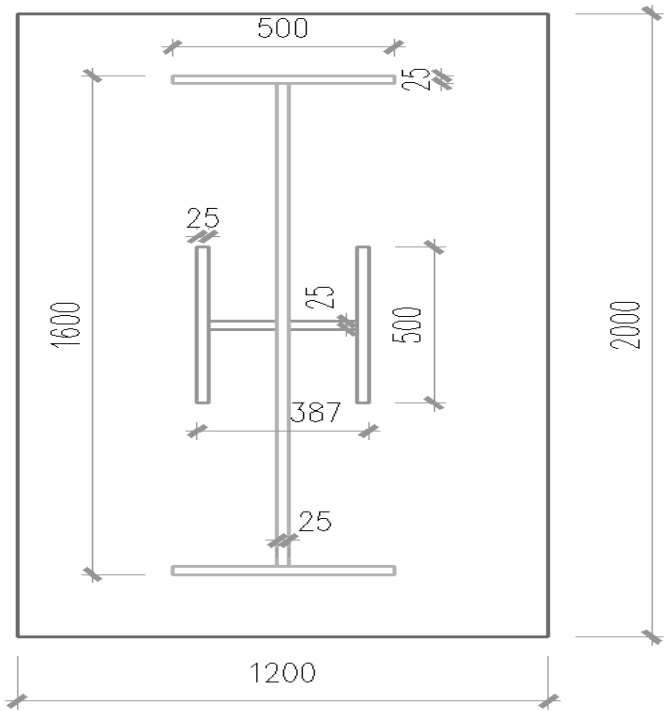

Figure 6 Sectional size of steel reinforced concrete giant column

\subsection{Load conditions}

In the process of form finding analysis, the self-weight of all structural components needs to be considered first. The Midas program recognizes the length of the component as the distance between the node and the node in the structure. The bulk density and cross-sectional area of the material are defined in the program. The self-weight of the component will be accurately calculated by the program. Overweight nodes act on the structure through additional dead loads. In addition to the weight of the member, the loads that need to be considered are divided into the following parts:

(1) The dead weight load of the $50 \mathrm{KN}$ equivalent node connecting the inner ring cable and the radial cable head.

(2) The self-weight load of the $20 \mathrm{KN}$ equivalent node connecting the radial cable and the ring truss.

(3) The self-weight of the structural cable clamp shall be loaded on the connection node of the radial cable and the structural cable according to $2.3 \mathrm{KN}$.

(4) The self-weight load of the riding track is divided into the self-weight of the hoop riding track and the self-weight of the radial riding track, which are unified according to $2.6 \mathrm{KN} / \mathrm{m}$; the self-weight of the hoop riding track is loaded on the radial cable in the form of point load, and the self-weight of the radial riding track form is loaded on the ring truss and the inner ring cable.

(5) The weight of the sound box, the spans are arranged under the radial cable, there are 8 in total, and each load is considered as $8 \mathrm{KN}$.

(6) The self-weight of the luminaire is superimposed with the self-key load of the ring road at $1.03 \mathrm{KN} / \mathrm{m}$.

\subsection{Boundary conditions}

The external truss of the model is hinged with the steel-concrete giant column in three directions, and the outer end of the stabilizer cable is hinged with the steel-concrete giant column in three directions. The lower ends of all the steel-concrete giant columns are restricted in horizontal and rotational freedom.

\section{Model modeling and form- finding process}

The model first draws a three-dimensional diagram of the outer truss cable net structure through the CAD three-dimensional drawing function. To reduce the cable force difference of the ellipse inner ring, the four-point drawing ellipse method is used to fit the ellipse inner ring. In this case, the structure is divided into four In the area, the radial cables of each area are distributed radially around the corresponding circle center, and try to ensure that the projection length of each radial cable plane is equal, in this way, the outer ring is also fitted with four arcs to form an ellipse, so that the shape of the inner and outer ring is strictly similar to ensure that the bending moment of the outer ring is not too large, and the cable force is evenly distributed, which is conducive to the anti-slip design of the later cable clamp nodes [5].

After that, the CAD model file is imported into Midas Gen, and the components are assigned attributes, loads, and boundary conditions in sequence according to the above model parameters. The membrane material and the steel concrete giant column are created in Midas Gen, and the new model file is imported into Midas Civil.

Model form-finding analysis is through Midas Civil's suspension bridge analysis function. The new model file is imported into Civil, and the update node group and vertical point group are set in Civil. All nodes except the support node are defined as the update node group. Nodes are defined as vertical point groups. The suspension bridge analysis method selects the initial internal force method, the number of iterations is 100 , and the suspension bridge analysis is run. The prestress distribution and the adjusted geometric configuration obtained through the suspension bridge analysis are extracted, and the prestress addition and geometric configuration are performed on the Midas Gen model. The revised state is initially determined to be the zero state of the structural model.

Finally, the zero state is verified, that is, considering 
the geometric nonlinearity, the zero state is subjected to a nonlinear analysis under the prestress and the structure's own weight to judge the vertical displacement difference of the structure in the initial state and the internal force distribution of the component, and judge whether the initial state meets the design requirements.

\section{Form-finding analysis results}

\subsection{Displacement results}

Fig. 7-8 shows the deformation of the structural model in the initial state. The displacement of the cable net in the initial state is very small, the maximum deformation is less than $2 \mathrm{~mm}$, the ring truss produces the maximum deformation of less than $1 \mathrm{~mm}$, and the maximum deformation is concentrated at both ends of the short axis of the ellipse and near the node where the sound box's weight is applied, which accords with the assumption of force. Therefore, it can be concluded that the geometric configuration before and after the shape finding is basically the same.

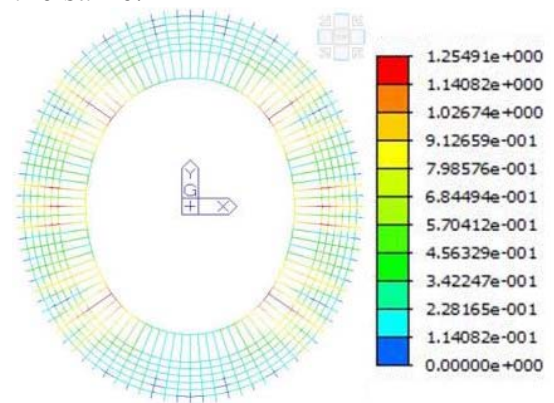

Figure 7 Displacement and deformation of cable net

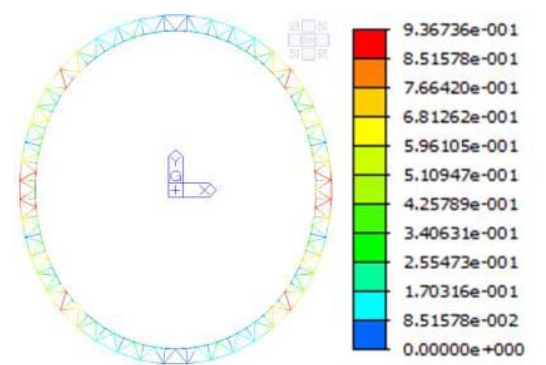

Figure 8 Displacement and deformation of outer truss

\subsection{Internal force distribution results}

Fig. 9-12 shows the internal force distribution of the structural members in the initial state. It can be seen that the load-bearing cable force is between $1241 \mathrm{KN} \sim$ $3289 \mathrm{KN}$, the stable cable force is between $392 \mathrm{KN} \sim$ $1225 \mathrm{KN}$, and the inner ring cable force is between $24020 \mathrm{KN} \sim 24069 \mathrm{KN}$. The cable force of the hoop structure is between $0 \mathrm{KN} \sim 38 \mathrm{KN}$. The maximum internal force and minimum internal force of the load-bearing cable are on the north-south side and the east-west side respectively. The maximum internal force of the stabilizer cable and the inner ring cable is near the node where the speaker's own weight is applied. The difference between the maximum cable force and the minimum cable force of the inner ring cable is less than $50 \mathrm{KN}$, and the largest increment of the cable force is $0.2 \%$, which shows that the internal force distribution of the inner loop cable is relatively uniform. Fig. 13 shows the internal stress distribution of the membrane, where the initial maximum internal force of the membrane is 79 KPa. Fig. 14 shows the internal force distribution of the outer truss.

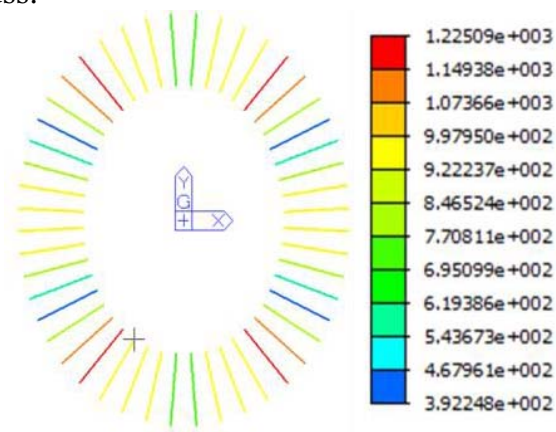

Figure 9 Internal force distribution of load-bearing cable

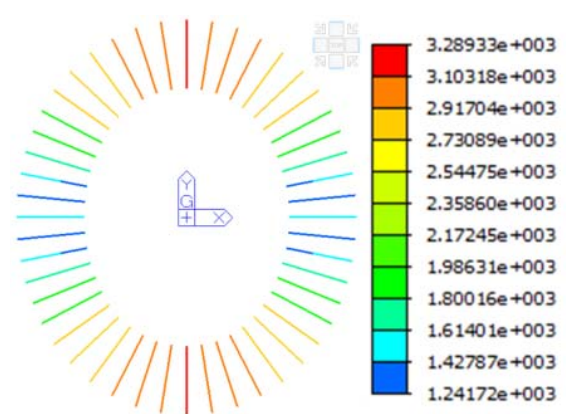

Figure 10 Internal force distribution of stable cable

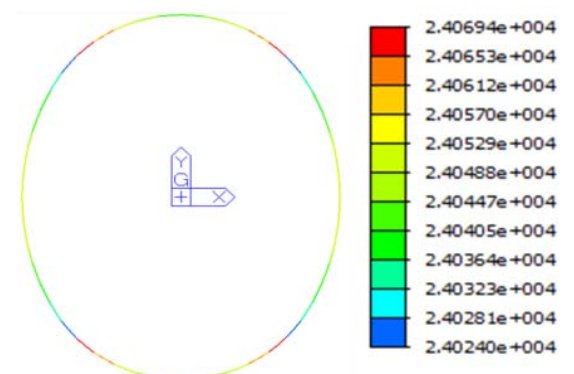

Figure 11 Internal force distribution of inner ring cable

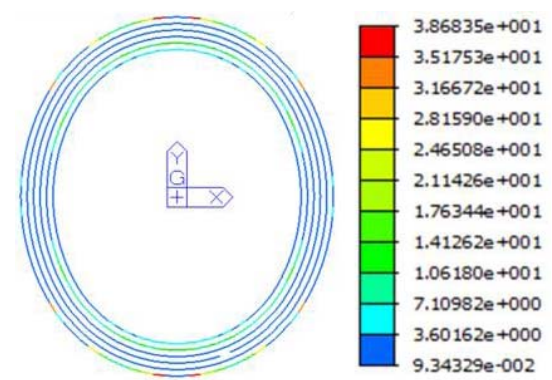

Figure 12 Internal force distribution of structural cables 


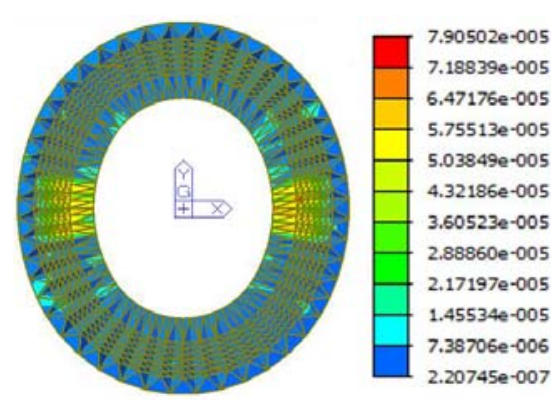

Figure 13 Stress distribution of membrane material

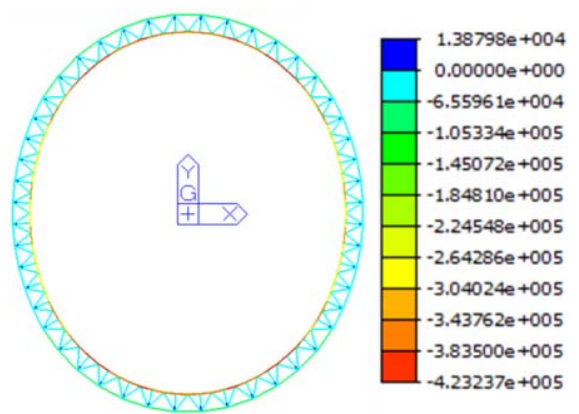

Figure 14 Internal force distribution of external truss

\subsection{Maximum cable force for form- finding analysis}

According to "Technical Regulations for Cable Structures" [6], the bearing capacity of roof cable structures is checked according to formula (1), where $N_{d}$ is the cable force envelope value obtained by nonlinear calculation of each load combination, and the importance coefficient $\gamma_{0}$ is $1.1 ; F$ is the design value of the cable's bearing capacity, which is calculated according to formula (2), where $F_{t k}$ is the minimum breaking force of the cable. The specific values are shown in Table 1, and $\gamma_{R}$ is the partial coefficient of the cable resistance, which is taken as 2.0.

$$
\begin{gathered}
\gamma_{0} N_{d} \leq F \\
F=\frac{F_{t k}}{\gamma_{R}}
\end{gathered}
$$

Table 1 Maximum cable force of cable under form-finding

\begin{tabular}{ccccccc}
\hline Type & Specification & $\begin{array}{c}\text { Effective } \\
\text { cross-sectional } \\
\text { area } / \mathrm{mm}^{2}\end{array}$ & $\begin{array}{c}\text { Equivalent } \\
\text { circular section } \\
\text { radius } / \mathrm{mm}\end{array}$ & $\begin{array}{c}\text { Minimum breaking } \\
\text { force } \\
/ \mathrm{KN}\end{array}$ & $\begin{array}{c}\text { Maximum } \\
\text { cable force in } \\
\text { form finding } \\
/ \mathrm{KN}\end{array}$ & $\begin{array}{c}\text { Safety } \\
\text { factor }\end{array}$ \\
\hline $\begin{array}{c}\text { Inner cable } \\
\text { Load }\end{array}$ & $10 \phi 118$ & 97300 & 175.99 & 141000 & 24069 & 5.86 \\
cable & $\phi 138$ & 11100 & 55.94 & 17200 & 3289 & 5.23 \\
$\begin{array}{c}\text { Stable } \\
\text { cable }\end{array}$ & $\phi 114$ & 7540 & 48.99 & 11700 & 1932 & 6.06 \\
$\begin{array}{c}\text { Structure } \\
\text { cable }\end{array}$ & $\phi 110$ & 7020 & 47.28 & 10306 & 1225 & 8.42 \\
\hline
\end{tabular}

After the form-finding analysis, the cable strength is checked and calculated. The safety factors obtained in Table 1 are all greater than 2.2, which is far from the limit of the cable breaking force and has sufficient margin.

\section{Conclusion}

The form-finding analysis of the structural model by Midas finite element software, mainly draws the following conclusions:

(1) In the form-finding analysis, the maximum initial displacement of the cable net is less than $2 \mathrm{~mm}$, and the maximum deformation of the ring truss is less than $1 \mathrm{~mm}$. Therefore, the geometric configuration before and after the form-finding is basically the same. This initial state can be used for subsequent load state analysis and construction process analysis.

(2) The difference between the maximum cable force and the minimum cable force on the inner loop cable is less than $50 \mathrm{KN}$, the maximum increase in cable force is $0.2 \%$, and the internal force of the inner loop cable is evenly distributed due to the four-point circle method.

(3) After the form-finding analysis, a simple cable fracture calculation is performed to determine that the initial cable force is far from the fracture requirement, which provides a large amount of cable force surplus for the later load state analysis.

\section{References}

1. Zhang Qilin. Cable and membrane structure $[\mathrm{M}]$. Shanghai: Tongji University Press, 2002.1-14

2. Monday Monday, Chen Lianlian. Talking about the history and trend of the development of the overall structure of tension and tension $[\mathrm{J}]$. Space Structure, 2013, 19(04): 11-17.

3. Feng Hong, Qian Suping, Yuan Yong. Summary and Prospects of Theoretical Research on Cable and Membrane Structure Analysis [J].Journal of Tongji 
University (Natural Science Edition), 2002(09): 1033- 1037.

4. Xia Chen. Research on performance analysis and design key technology of spoke-type saddle-shaped single-layer cable net structure [D]. Southeast University, 2016.
5. Wang Kun. Research and design of the body shape of the car-spoke tension structure[D]. Tsinghua University, 2011.

6. China Academy of Building Research. JGJ 257-2012. Technical Specification for Cable Structure [S]. Beijing: China Building Industry Press, 2012 